\title{
Sobre a causalidade na relaxação dielétrica
}

Em artigo aparecido nesta revista 1, o seu autor, Prof. Renê Robert, introduz um retardo, t/, na equação diferencial de Debye (ou Pellat (1), ou D-P), que seria então dada por

$$
\tau \frac{d P(t)}{d t}=\chi \epsilon_{0} E(t)-P\left(t-t^{\prime}\right)
$$

sendo $\chi$ a susceptibilidade, $\epsilon_{0}$ a permitividade do vácuo, $E$ o campo aplicado (simetria plana), $P$ a polarização elétrica, e $\tau$ o chamado tempo de relaxação. Embora não concordemos com a afirmativa contida em (1) de que a introdução do retardo na Eq. (1) é necessária para garantir a causalidade do processo de polarização, vamos antes mostrar que o tipo de retardo proposto daria às respostas dielétricas característica bem diferente daquela usualmente observada.

A característica do retardo dielétrico: a característica da resposta dielétrica se evidencia na sua reação a um campo elétrico em forma de degrau, de amplitude $E_{0}$ aplicado, vamos dizer, em $t=0$. A solução da Eq. (1), com $t$ l $=0$, isto é, sem retardo, é $P(t)=\chi \epsilon_{0} E_{0}(1-\exp (-v t)$, com $v=1 / \tau$. A Eq. (1) sem retardo estabelece que a velocidade de polarização é proporcional à diferença entre a polarização atingível, $\chi \epsilon_{0} E_{0}$, e a polarização efetivamente atual, $P(t)$. É interessante notar que se a constante de proporcionalidade $v$, em vez de constante, for uma função decrescente do tempo - como se o ímpeto à polarização decrescesse do momento da aplicação do degrau -, a solução se escreveria $\chi \epsilon_{0} E_{0}(1-\exp (-T))$, com $T=\int_{0}^{t} v(t \prime) d t$. Característicamente, a velocidade de polarização decresce após a aplicação do degrau de campo elétrico.

$O$ retardo sugerido em (1): Em (1) soluções da Eq. (1) foram apresentadas, isto é, com o retardo $t$ ' superposto ao próprio retardo dielétrico. Porém, será mais simples estudar o efeito deste retardo conceitualmente deixando-o agir isoladamente. Então ter-se-ia que a resposta à aplicação do degrau em $t=0$ seria a polarização $P(t)$

$$
\begin{array}{ll}
P(t)=0, & 0<t<\tau \text { e } \\
P(t)=\chi \epsilon_{0} E_{0}, & \text { para } t>\tau .
\end{array}
$$

Note-se que este degrau deslocado no tempo configuraria um tipo de resposta diametralmente oposta àquela apresentada pelos dielétricos usuais, como exposto acima, pois a velocidade de polarização, nula entre 0 e $\tau$, cresceria nas vizinhancas de $\tau_{-}$, tornando-se uma função $\delta(t-\tau)$.

Portanto conclúimos que o retardo sugerido em (1) não parece compatível com o que se conhece de polarização em dielétricos reais. Mas o seu conteúdo pode ser de utilidade em outras áreas.

G.F. Leal Ferreira

IF/USP, São Carlos

\section{Resposta do autor}

Meus objetivos no trabalho [1] foram chamar atenção para a validade do princípio de causalidade (causa e efeito) e mostrar técnicas de integração de uma equação diferencial conhecida como "delay differential equation" a qual tem inúmeras aplicações. Ambos os tópicos acima mencionados foram desenvolvidos baseados nas idéias propostas nas Refs. 5 e 6 do artigo [1]. O modelo de Debye-Pellat foi usado por ser matematicamente simples. Aliás, este modelo é pouco usado atualmente pois não leva em conta a interação entre dipolos que existe num dielétrico real. Existem atualmente diversos modelos mais adequados. Relativamente às observações do Prof. Guilherme, estas são aceitáveis como aquelas propostas pelo Prof. B. Gross e R.S. Rocha publicadas nos Anais da Academia Brasileira de Ciências.

Renê Robert

Departamento de Eletricidade/UFPR rene@lactec.org.br

\section{Referências}

[1] R. Robert, Rev. Bras. Ensino Física 26, 237 (2004). 